\title{
Qualidade fisiológica de sementes de garapa (Apuleia leiocarpa) submetidas ao envelhecimento acelerado
}

\author{
Marcone Moreira Santos ${ }^{1 *}$ \\ Glauciana da Mata Ataíde ${ }^{2}$ \\ Raquel Maria de Oliveira Pires ${ }^{3}$ \\ ${ }^{1}$ Departamento de Engenharia Florestal, Universidade Federal de Viçosa \\ Avenida Perdue, Campus Universitário, CEP 36.570-900, Viçosa - MG, Brasil \\ ${ }^{2}$ Departamento de Ciência Agrária, Universidade Federal de São João Del Rei \\ Sete Lagoas - MG, Brasil \\ ${ }^{3}$ Departamento de Agricultura, Universidade Federal de Lavras, Lavras - MG, Brasil \\ * Autor para correspondência \\ marconemoreirasantos@hotmail.com
}

Submetido em 14/03/2019

Aceito para publicação em 06/08/2019

\section{Resumo}

Objetivou-se com este trabalho avaliar a germinação, o índice de velocidade de germinação (IVG), a viabilidade por meio do teste de tetrazólio e a condutividade elétrica (CE) das sementes de Apuleia leiocarpa submetidas ao envelhecimento acelerado (EA) bem como indicar os melhores testes para avaliar a qualidade fisiológica das sementes da referida espécie. As sementes foram envelhecidas pelos tempos de 0, 24, 48 e 72 $\mathrm{h}$ em câmara de envelhecimento a $48^{\circ} \mathrm{C}$. A qualidade fisiológica das sementes reduziu ainda nas primeiras 24 horas de envelhecimento. Os testes de tetrazólio e de Condutividade Elétrica (CE) foram eficientes para avaliar a perda da qualidade fisiológica das sementes de $A$. leiocarpa submetidas ao EA.

Palavras-chave: Condutividade elétrica; Germinação; Teste de tetrazólio

\section{Abstract}

Physiological quality of garapa seeds (Apuleia leiocarpa (Vogel) J. F. Macbr) submitted to accelerated aging. The objective of this study was to evaluate the germination rate, germination speed index and viability using the tetrazolium test and electrical conductivity in seeds of Apuleia leiocarpa subjected to accelerated aging, and we also determined the best tests to evaluate the quality of the seeds of this species. The seeds were aged for $0,24,48$ and 72 hours in an aging chamber at $48^{\circ} \mathrm{C}$. The physiological quality of the seeds decreased even in the first 24 hours of aging. The tetrazolium and electrical conductivity tests were effective in determining the physiological quality of $A$. leiocarpa seeds subjected to accelerated aging.

Key words: Electrical conductivity; Germination; Tetrazolium test 


\section{Introdução}

Apuleia leiocarpa (Vogel) J. F. Macbr, popularmente conhecida como garapa, é uma espécie arbórea, com 25 a $35 \mathrm{~m}$ de altura e 60 a $90 \mathrm{~cm}$ de diâmetro, de ocorrência na Floresta amazônica e Mata Atlântica. É recomendada para reposição de mata ciliar em locais sem inundação e apresenta madeira com alta qualidade, portanto, de grande importância para o setor madeireiro (LORENZI, 2008). Outros usos relevantes são fontes de energia, medicinal, ornamental, reflorestamento ambiental bem como produção de substâncias tanantes (CASTRO et al., 2017).

O potencial econômico e ambiental da A. leiocarpa aliado ao processo de devastação das florestas e ao lento processo de germinação para produção de mudas têm causado reduções significativas em suas populações (CARVALHO, 2008; LANGO; DORIGON 2012). Portanto, estudos que compreendam aspectos relacionados à germinação e fisiologia das sementes se tornam fundamentais para possibilitar a produção de mudas para fins conservacionistas e produtivos da garapa.

$\mathrm{O}$ vigor de sementes de diversas espécies pode ser avaliado pelo teste de envelhecimento acelerado (EA), cujo princípio baseia-se no fato de que sementes de maior vigor são mais tolerantes às altas temperaturas e à umidade relativa do ar (CARVALHO et al., 2016). No entanto, os procedimentos tradicionais para a interpretação dos resultados do teste de EA carecem de informações complementares porque considera o grau de sobrevivência das sementes, mas não preconiza observações para detectar outros possíveis efeitos do envelhecimento, como a queda da porcentagem e velocidade de germinação, atividade de enzimas desidrogenases e integridade das membranas celulares (MARCOS FILHO, 2005).

A insuficiência de conhecimento sobre a resposta germinativa de sementes e o desenvolvimento de plântulas de garapa frente às condições de alta temperatura e umidade relativa do ar no teste de envelhecimento acelerado ressaltam a necessidade da realização de trabalhos de pesquisa nessa área.
Diante do exposto, este trabalho teve como objetivo avaliar a germinação, índice de velocidade de germinação (IVG), a viabilidade por meio do teste de tetrazólio e a condutividade elétrica das sementes de $A$. leiocarpa submetidas ao envelhecimento acelerado bem como indicar os melhores testes para avaliar a qualidade fisiológica das sementes da referida espécie.

\section{Material e Métodos}

As sementes foram coletadas na região de Viçosa, Minas Gerais, Brasil (2045'17'S, 4252'57'W), em fevereiro de 2015, sendo beneficiadas e armazenadas em câmara fria $\left(5^{\circ} \mathrm{C}, \mathrm{UR}: 60 \%\right)$. Os experimentos foram conduzidos no Laboratório de Análises de Sementes Florestais do Departamento de Engenharia Florestal da Universidade Federal de Viçosa.

\section{Teor de água}

O teor de água foi determinado conforme metodologia prescrita nas Regras para Análise de Sementes (RAS) (BRASIL, 2009), utilizando o método da estufa, a $105 \pm 3^{\circ} \mathrm{C}$, por $24 \mathrm{~h}$, com cinco repetições de 20 sementes, sendo os resultados expressos em porcentagem (\%) b.u. (base úmida - relação entre a massa de água presente na semente e a massa total da semente) de teor de água.

\section{Envelhecimento acelerado}

Inicialmente as sementes foram submetidas ao tratamento de superação de dormência com imersão em ácido sulfúrico (PA) por 15 minutos e posteriormente lavadas abundantemente com água destilada e secas em temperatura ambiente por $24 \mathrm{~h}$.

O teste foi conduzido conforme descrito por Marcos Filho (1999), no qual se utilizaram caixas plásticas do tipo Gerbox ${ }^{\circledR}$, contendo no seu interior $40 \mathrm{~mL}$ de água destilada e uma tela metálica suspensa para dar suporte às sementes, evitando que elas tenham contato com a água. Após colocar as sementes suspensas, as caixas Gerbox ${ }^{\circledR}$ foram tampadas e mantidas no interior de câmaras de envelhecimento acelerado a $48^{\circ} \mathrm{C}$ por 0 (controle), 24 , 48 e $72 \mathrm{~h}$. 


\section{Germinação e IVG}

Após passar pelo EA, conforme as condições descritas, foi realizado o teste de germinação conduzido em placas de Petri. Como substrato, foram utilizadas duas folhas de papel tipo Germitest umedecidas com água destilada (3 vezes o peso do papel). As sementes foram desinfestadas com fungicida CAPTAN $(0,5 \%)$ por 2 minutos. Após a semeadura, as sementes foram mantidas em câmara de germinação tipo BOD com temperatura de $25^{\circ} \mathrm{C}$ sob luz constante por quatro dias. Foram consideradas germinadas sementes que emitiram raiz primária até o final da condução do teste. O IVG foi calculado conforme Maguire (1962).

Os experimentos de germinação e IVG foram realizados em delineamento inteiramente casualizado (DIC) com quatro tratamentos (tempos de EA).

\section{Teste de tetrazólio}

As sementes passaram pelo processo de EA, conforme descrito, e posteriormente foram submersas por $3 \mathrm{~h}$ em solução de 2,3,5 trifenil cloreto de tetrazólio (pH 6,5 a 7,0) nas concentrações de 0,05\%, em câmara tipo BOD a $25^{\circ} \mathrm{C}$, no escuro. Ao término do período de coloração, a solução foi drenada, as sementes lavadas em água corrente e mantidas submersas em água em geladeira até o momento da avaliação.

As sementes foram avaliadas uma a uma, seccionando-as longitudinalmente através do centro do eixo embrionário com auxílio de bisturi. Para a caracterização dos níveis de viabilidade foi elaborada uma representação de sementes viáveis e inviáveis, observando a presença e a localização do dano, além das condições físicas das estruturas embrionárias. A diferenciação de cores dos tecidos foi observada de acordo com os critérios estabelecidos para o teste de tetrazólio (BHÉRING et al., 1996; FRANÇA NETO, 1999): vermelho brilhante ou rosa (tecido vivo e vigoroso), vermelho-carmim forte (tecido em deterioração) e branco leitoso ou amarelado (tecido morto).

\section{Condutividade elétrica}

Para avaliação da condutividade elétrica, as sementes foram colocadas em Erlenmeyers com $75 \mathrm{~mL}$ de água deionizada a $25^{\circ} \mathrm{C}$, por $24 \mathrm{~h}$. A condutividade elétrica do lixiviado foi determinada utilizando-se condutivímetro MICRONAL, conforme procedimento descrito por Woodstock (1973). O resultado obtido foi expresso em $\mathrm{mScm}^{-1}$ semente $^{-1}$. Foram utilizadas cinco repetições de 30 sementes para cada tratamento.

Os experimentos foram realizados em delineamento inteiramente casualizado (DIC). Os dados obtidos foram submetidos à análise de variância e regressão no programa Statistica 10 (STATSOFT, 2010).

\section{Resultados}

As sementes de A. leiocarpa apresentaram um teor de água de $8,48 \%$. A porcentagem de germinação para as sementes não envelhecidas foi de $76 \%$, no entanto, esse percentual reduziu para $28 \%$ após 24 h de EA. Após $48 \mathrm{~h}$ de EA, as sementes perderam a capacidade de germinar (Figura 1A). O valor de IVG também sofreu redução significativa nas primeiras $24 \mathrm{~h}$ de EA, e zerou após 48 $\mathrm{h}$ de EA (Figura 1B).

Os resultados do teste de tetrazólio também indicaram a perda de viabilidade das sementes em decorrência do EA, conforme a Tabela 1.

De acordo com o teste de tetrazólio, as sementes mortas apresentaram coloração branca leitosa ou amarelada para os tecidos mortos, vermelho brilhante ou rosa para tecidos viáveis e vermelho carmim para tecidos em deterioração (Figura 2).

Os valores de condutividade elétrica variaram de 10,4 até 13,85 $\mathrm{mScm}^{-1}$ semente $^{-1}$ durante o EA (Figura 3). 
FIGURA 1: Porcentagem de germinação (A) e Índice de Velocidade de Germinação (B) de sementes de Apuleia leiocarpa submetidas ao Envelhecimento Acelerado (EA).

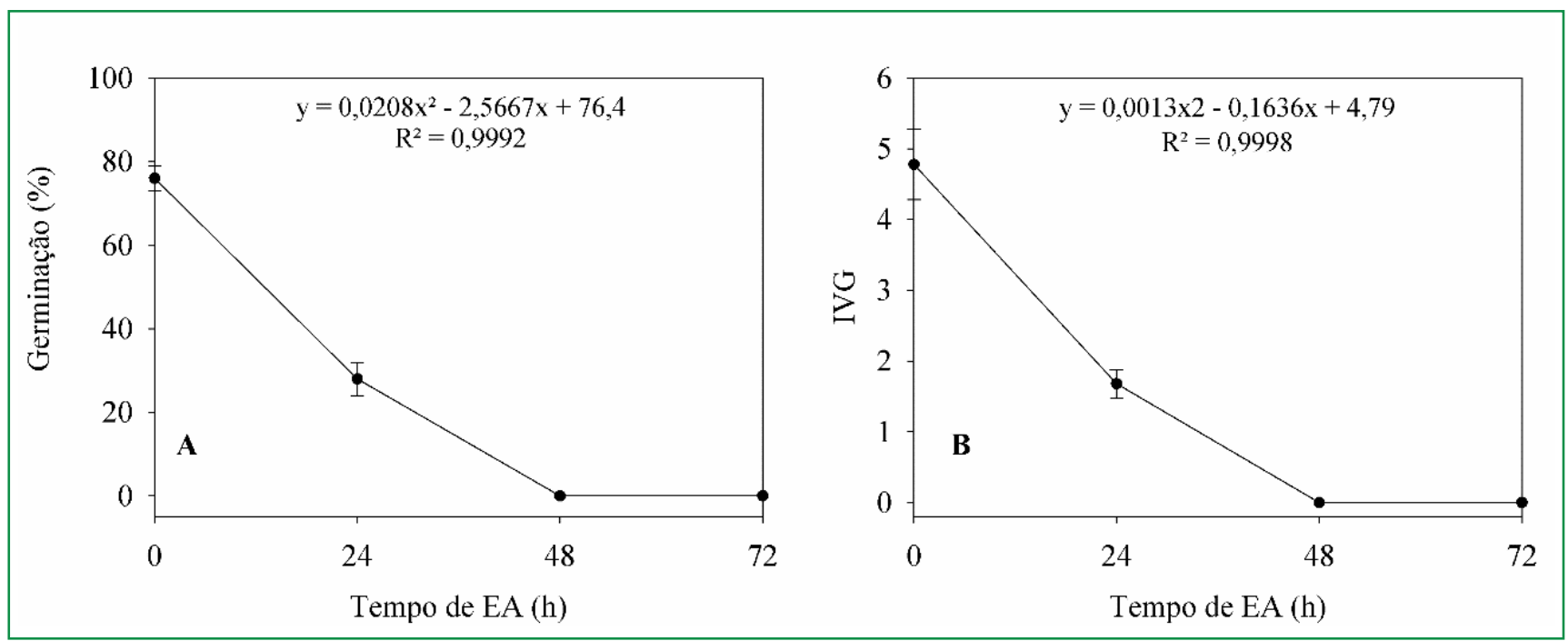

TABELA 1: Porcentagem de sementes viáveis (SV), sementes mortas (SM) e Sementes em deterioração (SD) durante o EA de acordo com o teste de tetrazólio.

\begin{tabular}{cccc}
\hline Tempo de EA & SV $(\%)$ & SM $(\%)$ & SD $(\%)$ \\
\hline 0 & $78 \mathrm{a}$ & $21 \mathrm{c}$ & $1 \mathrm{c}$ \\
24 & $32 \mathrm{~b}$ & $23 \mathrm{c}$ & $45 \mathrm{~b}$ \\
48 & $0 \mathrm{c}$ & $4 \mathrm{~b}$ & $65 \mathrm{a}$ \\
72 & $0 \mathrm{c}$ & $88 \mathrm{c}$ & $12 \mathrm{c}$ \\
\hline
\end{tabular}

Médias seguidas da mesma letra na coluna não se diferem estatisticamente de acordo com teste de Tukey 5\%.

FIGURA 2: Aspecto geral da coloração de sementes de A. leiocarpa após coloração com tetrazólio. Semente morta (A), Semente viável (B e C) e semente em deterioração (D)
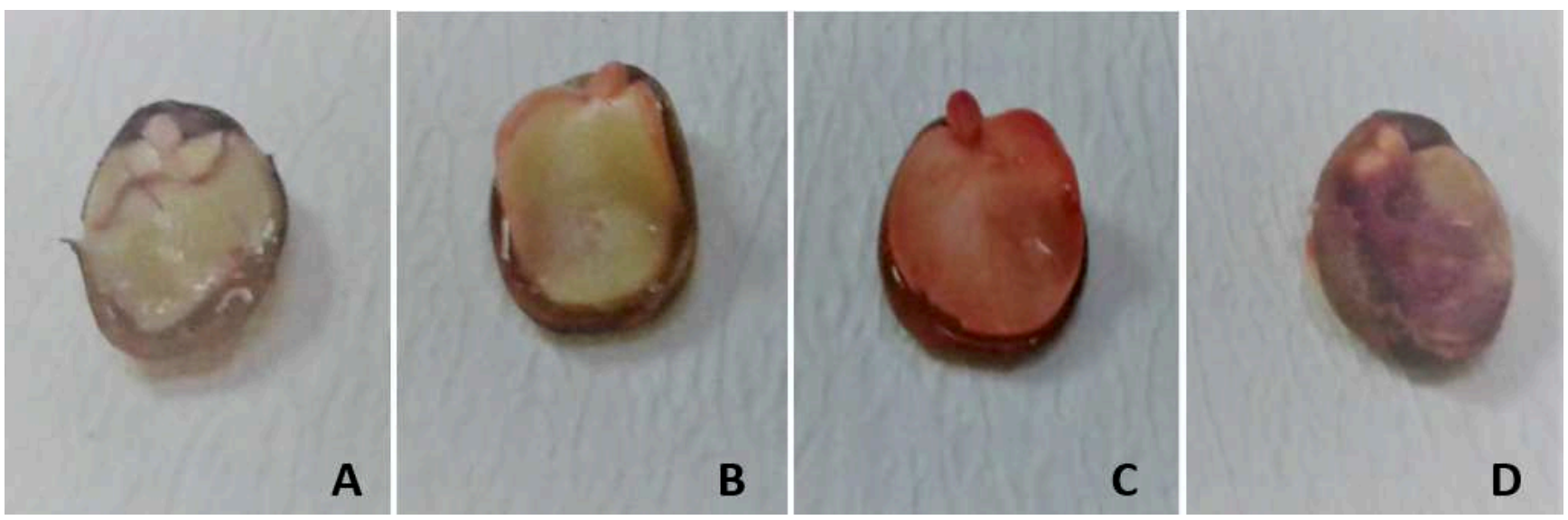
FIGURA 3: Valores de condutividade elétrica (CE) de sementes de Apuleia leiocarpa durante o envelhecimento acelerado (EA).

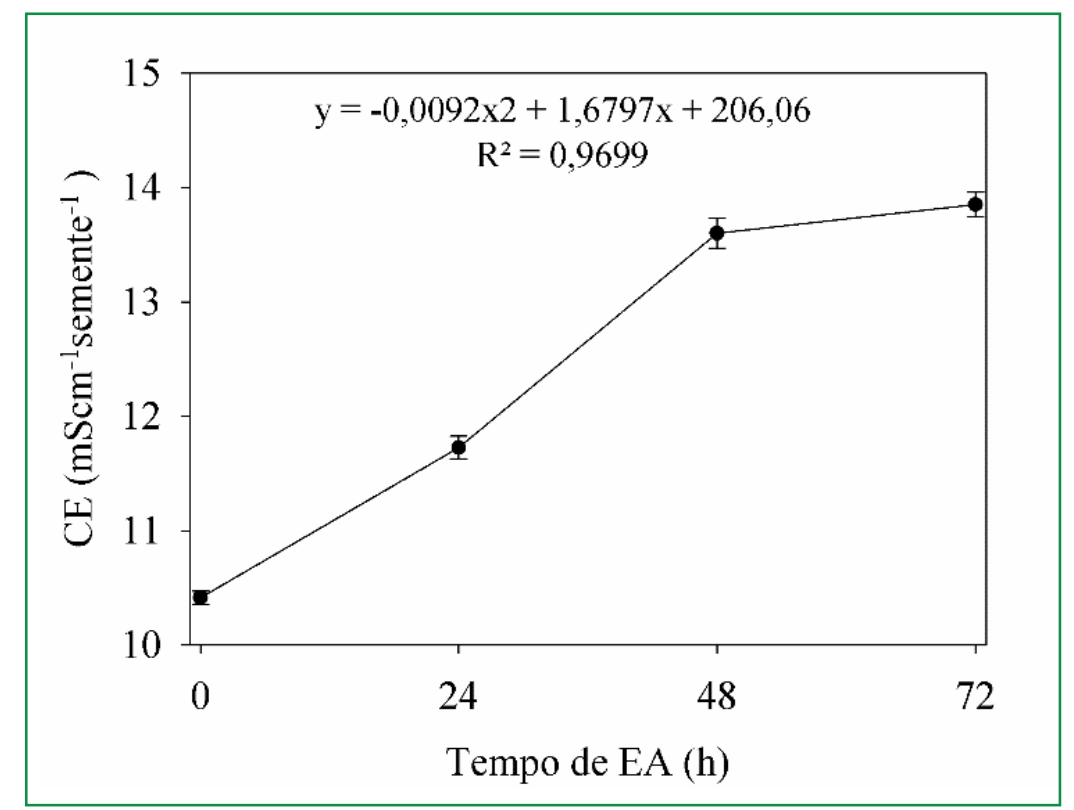

\section{Discussão}

Os valores do teor de água $(8,48 \%)$ e germinação (78\%) nas sementes de garapa não envelhecidas estão de acordo com aqueles encontrados por Spadeto et al. (2018). O procedimento de imersão em ácido sulfúrico (PA) possibilitou a superação do mecanismo de dormência tegumentar existente nas sementes de $A$. leiocarpa (CASTRO et al., 2017).

Embora o lote de sementes tenha apresentado um bom desempenho germinativo inicial, o percentual de germinação reduziu significativamente nas primeiras 24 $\mathrm{h}$ de $\mathrm{EA}$ a $48^{\circ} \mathrm{C}$. Tais resultados indicam que condições de alta temperatura e umidade favorecem o processo de deterioração das sementes de A. leiocarpa. A amplitude de temperatura em que ocorre a germinação varia para cada espécie, existindo as limitantes e ótimas. De modo geral, a faixa de $20^{\circ} \mathrm{C}$ a $30^{\circ} \mathrm{C}$ é a adequada para a germinação de grande número de espécies subtropicais e tropicais (LONE et al., 2010).

A germinação envolve uma série de processos físicos, fisiológicos e bioquímicos relativamente complexos (BEWLEY et al., 2013). Durante a embebição ocorrem alterações nas células do embrião envolvendo espécies reativas de oxigênio (EROs), proteínas e enzimas capazes de alterar as características da parede e uma série de eventos fisiológicos, bioquímicos e moleculares capazes de regular o processo, portanto, a temperatura e umidade são os principais fatores capazes de regular a germinação (BEWLEY et al., 2013; YAN et al., 2013).

Trabalhos com outras espécies florestais como: Piptadenia moniliformis (AQUINO et al., 2018), Handroanthus heptaphyllus (LAMARCA; BARBEDO, 2017), Peltophorum dubium (PADILHA et al., 2018) e Mabea fistulifera (JUNIOR; LOPES, 2017) comprovam o efeito negativo do envelhecimento acelerado sobre a germinação e emergência de plântulas.

A redução da qualidade fisiológica das sementes de garapa submetidas à EA se deve, provavelmente, à ocorrência de danos oxidativos irreversíveis provocados pela ação de radicais livres nos processos respiratórios e de reações deletérias dos constituintes celulares que ocorrem em condições de altas temperaturas (SANTOS et al., 2017). Além dos danos oxidativos, condições de altas temperaturas causam a desnaturação de enzimas reguladoras do processo germinativo (ATAÍDE et al., 2016; SANTOS, 2018). 
Com o aumento do tempo de permanência das sementes nas condições de envelhecimento, a germinação foi afetada negativamente, pois o aumento da temperatura ou do tempo de exposição a condições de estresse térmico causou maior desordem no metabolismo das sementes de garapa.

A perda da viabilidade das sementes durante o EA foi evidenciada pelo teste de tetrazólio, pois o teste é definido como uma avaliação bioquímica, baseada na atividade das enzimas desidrogenases que catalisam as reações respiratórias, presentes nas mitocôndrias, localizadas no interior das células vegetais. Assim, na respiração celular, há liberação de íons hidrogênio, que reagem com o sal de Tetrazólio produzindo o composto de cor vermelha e insolúvel, trifenilformaza (GARLET et al., 2015).

Embora o teste de tetrazólio seja definido como um teste de viabilidade e não vigor, a combinação deste com outros testes pode fornecer informações importantes quanto ao vigor e à qualidade fisiológica de um lote de sementes. Por intermédio da coloração, ele permite identificar sementes mortas, viáveis e em estágio de deterioração (SILVA et al., 2016).

Apesar de existirem trabalhos de padronização do teste de tetrazólio para algumas espécies florestais, as técnicas ainda não estão completamente estabelecidas. No entanto, o teste já se mostrou eficiente em espécies como: Albizia hasslerii (DUBOC et al., 2018), Ceiba speciosa (SILVA, 2017), Tabernaemontana fuchsiaefolia (MORAES et al., 2016) e Cassia leptophylla (GARLET et al., 2015).

Além de ser determinante na germinação, a temperatura exerce influência na condutividade elétrica das sementes durante a embebição. $\mathrm{O}$ valor da condutividade está relacionado com a quantidade de lixiviados na solução, sendo diretamente relacionado com a integridade das membranas celulares (SANTOS et al., 2017).

O envelhecimento gera uma série de reações oxidativas, produzindo peroxidação de lipídeos e peroxidação não enzimática, ocasionando perda de reservas e degradação de metabólitos essenciais para germinação (MORAES et al., 2016). Assim, maiores valores de CE em sementes de $A$. leiocarpa envelhecidas indicam maior lixiviação de solutos devido à alteração da integridade das membranas celulares, reduzindo o vigor das sementes. Por essa razão, a condutividade elétrica tem sido proposta como parâmetro a ser utilizado nos testes de qualidade fisiológica das sementes.

De modo geral, pode-se dizer que, assim como a germinação e IVG, os testes de tetrazólio e condutividade elétrica foram eficientes para avaliar a deterioração e perda da qualidade de sementes de A. leiocarpa durante o envelhecimento acelerado. Embora a germinação e IVG sejam considerados testes mais precisos, o tetrazólio e CE podem fornecer informações precisas sobre a qualidade das sementes da referida espécie em laboratório de maneira rápida, eficiente, sendo alternativa para testes de germinação que muitas vezes são demorados e inviáveis.

A partir dos resultados foi possível concluir que o EA afetou a germinação e o IVG ainda nas primeiras 24 $\mathrm{h}$ e comprometeu integralmente a germinação ao final de $72 \mathrm{~h}$ e que o teste de tetrazólio, dentro das condições testadas, se mostrou eficiente para avaliar a viabilidade das sementes de A. leiocarpa. Para o teste de CE, esse também foi eficiente para avaliar a perda da qualidade fisiológicas das sementes de A. leiocarpa.

\section{Referências}

AQUINO, G. S. M.; BENEDITO, C. P.; PEREIRA, K. T. O.; SANTOS, P. C. da S.; OLIVEIRA, J. C. D. de. Accelerated aging of Piptadenia moniliformis (Benth.) seeds. Revista Caatinga, Mossoró, v. 31, n. 3, p. 681-686, 2018.

ATAIIDE, G. M.; BORGES, E. E. L.; GONÇALVES, J. F. C.; GUIMARÃES, V. M.; FLORES, A. V. Alterações fisiológicas durante a hidratação de sementes de Dalbergia nigra ((Vell.) Fr. All. ex Benth.). Ciência Florestal, Santa Maria, v. 26, n. 2, p. 615625, 2016.

BEWLEY, J. D.; BRADFORD, K. J.; HILHORST, H. W. M.; NONOGAKI, H. Seeds: physiology of development, germination and dormancy. 3 ed. New York: Springer, 2013. 392 p.

BHÉRING, M. C.; SILVA, R. F.; ALVARENGA, E. M.; DIAS, D. N. F. S.; PENA, M. F. Avaliação da viabilidade e do vigor de sementes de feijão de vagem (Phaseolus vulgaris $\mathbf{L}$.) pelo teste de tetrazólio. Viçosa: Boletim Técnico UFV, 1996. 27 p.

BRASIL - MINISTÉRIO DA AGRICULTURA, PECUÁRIA E ABASTECIMENTO. Regras para análise de sementes. Brasília: SNDA/DNPV/CLAV, 2009. 398 p. 
CARVALHO, C. A.; SILVA, J. B.; ALVES, C. Z. Envelhecimento acelerado em sementes de mogno. Revista Ciência Agronômica, Fortaleza, v. 47, n. 4, p. 691-699, 2016.

CARVALHO, P. E. R. Espécies arbóreas brasileiras. Brasília: Embrapa Informação Tecnológica, 2008. 593 p.

CASTRO, D. S.; ARAUJO, E. F.; BORGES, E. E. L.; AMARO, H. T. R. Caracterização da testa de sementes de Apuleia leiocarpa após superação de dormência. Ciência Florestal, Santa Maria, v. 27, n. 3, p. 1061-1068, 2017.

DUBOC, E.; SILVEIRA, M. C. A.; NASCENTES, T. F. Avaliação da qualidade de sementes de farinha-seca (Albizia hasslerii) pelo teste de tetrazólio. Cadernos de Agroecologia, Recife, v. 13, n. 2, p. 1-9, 2018.

FRANÇA NETO, J. B. Teste de tetrazólio para determinação do vigor de sementes. In: KRZYZANOWSKI, F. C.; VIEIRA, R. D.; FRANÇA NETO, J. B. (Ed.). Vigor de sementes: conceitos e testes. Londrina: ABRATES, 1999. p. 66-72.

GARLET, J.; SOUZA, G. F.; DELAZERI, P. Teste de tetrazólio em sementes de Cassia leptophylla. Enciclopédia Biosfera, Goiânia, v. 11, n. 21 , p. 1800-1808, 2015.

JUNIOR, D. G.; LOPES, J. C. Teste de envelhecimento acelerado para avaliar o potencial fisiológico de sementes de canudo-de-pito. Ciência Florestal, Santa Maria, v. 27, n. 4, p. 1105-1115, 2017.

LAMARCA, E. V.; BARBEDO, C. J. Acerca da utilização do método científico nas pesquisas com sementes florestais: o envelhecimento acelerado em sementes de ipê-roxo, um modelo descritivo. Revista Ibirapuera, São Paulo, v. 1 n. 13, p. 47-55, 2017.

LANGO, A. P.; DORIGON, E. B. Emissão de brotos em germinação de Apuleia leiocarpa Vog. Macbride, com a utilização de extratos de Cyperus rotundus L. e Saintpaulia ionantha Wendl. para uso em miniestaquia. Unoesc \& Ciência - ACBS, Joaçaba, v. 3, n. 1, p. 47-56, 2012.

LONE, A. B.; SOUZA, G. R. B.; OLIVEIRA, K. S.; TAKAHASHI, L. A. S.; FARIA. R. T. Temperatura e substrato para germinação de sementes de flor-de-maio (Schlumbergera truncata (Haw.) Moran). Revista Ceres, Viçosa, v. 57, n. 3, p. 367-371, 2010.

LORENZI, H. Árvores brasileiras: manual de identificação e cultivo de plantas arbóreas nativas do Brasil. 5. ed. Nova Odessa: Instituto Plantarum, 2008. 368 p.

MAGUIRE, J. D. Speeds of germination-aid selection and evaluation for seedling emergence and vigor. Crop Science, Madison, v. 2, p. 176-177, 1962.

MARCOS FILHO, J. Testes de vigor: importância e utilização. In: KRZYZANOWSKI, F. C.; VIEIRA, R. D.; FRANÇA NETO, J. B. (Ed.). Vigor de sementes: conceitos e testes. Londrina: Abrates, 1999. p. 1-21.
MARCOS FILHO, J. Fisiologia de sementes de plantas cultivadas. Piracicaba: Fealq, 2005. 495 p.

MORAES, C. E.; LOPES, J. C.; FARIAS, C. C. M.; MACIEL, K. S. Qualidade fisiológica de sementes de Tabernaemontana fuchsiaefolia em função do teste de envelhecimento acelerado. Ciência Florestal, Santa Maria, v. 26, n. 1, p. 213-223, 2016.

PADILHA, M. S.; OLIVEIRA, A. S. M.; SOBRAL, L. S. Teste de envelhecimento acelerado em sementes de Peltophorum dubium Sprengel Taubert. Revista Thema, Pelotas, v. 15, n. 3, p. 11151122, 2018.

SANTOS, M. M. Germinação de sementes de Melanoxylon brauna Shott. sob estresse térmico e as consequências fisiológicas, anatômicas e bioquímicas. 2018. 83 f. Tese (Doutorado em Ciência Florestal) - Universidade Federal de Viçosa, Viçosa. 2018. SANTOS, M. M.; BORGES, E. E. L.; ATAÍDE, G. M.; SOUZA, G. A. Germination of seeds of Melanoxylon brauna Schott. under Heat stress: production of reactive oxygen species and antioxidant activity. Forests, Basel, v. 8, n. 405, p. 1-13, 2017.

SILVA, B.A.; NOGUEIRA, J. L.; VIEIRA, E. S. N.; PANOBIANCO, M. Critérios para condução do teste de tetrazólio em sementes de araucária. Pesquisa Agropecuária Brasileira, Brasília, v. 51, n. 1, p. 61-68, 2016.

SILVA, P. F. Determinação da qualidade fisiológica de sementes de Ceiba speciosa (A.St.-Hil.) Ravenna armazenadas através do teste de envelhecimento acelerado. 2017. $36 \mathrm{f}$. Trabalho de Conclusão de Curso (Bacharelado em Engenharia Florestal) Universidade de Brasília, Brasília. 2017.

SPADETO, C.; GOLIN, L. H.; PAUlUCIO, M. C.; LOPES, J. C. Embebição, osmocondicionamento e viabilidade de sementes de Apuleia leiocarpa (VOGEL.) J. F. MACBR. Ciência Florestal, Santa Maria, v. 28, n. 1, p. 80-89, 2018.

STATSOFT. Statistica 9.1 for Windows. Tusla: StatSoft Inc., 2010.

WOODSTOCK, L. M. Physiological and biochemical of seed vigor. Seed Science and Technolology, Zurich, v. 1, n. 1, p. $127-$ $157,1973$.

YAN, Y.; SHAPIRO, A. P.; HALLER, S.; KATRAGADDA, V.; LIU, L.; TIAN, J.; BASRUR, V.; MALHOTRA, D.; XIE, Z.; ARAHAM, N. G.; SHAPIRO, J. I.; LUI, J. Involvement of reactive oxygen species in a feed-forward mechanism of $\mathrm{Na} / \mathrm{K}$-ATPase-mediated signaling transduction. Journal of Biological Chemistry, La Jolla, v. 288, n. 47, p. 34249-34258, 2013. 